\title{
Canadian trend in surgical management of benign prostatic hyperplasia and laser therapy from 2007-2008 to 2011-2012
}

\author{
Pierre-Alain Hueber, MD, PhD; Kevin C. Zorn, MD \\ Section of Urology, Department of Surgery, Centre Hospitalier de l'Université de Montréal, Montréal, QC
}

Cite as: Can Urol Assoc J 2013;7(9-10):e582-6. http://dx.doi.org/10.5489/cuaj.203

Published online September 10, 2013.

\section{Abstract}

Introduction: Clinically benign prostatic hyperplasia (BPH) is classically associated by the progressive development of lower urinary tract symptoms (LUTS). The incidence of bothersome LUTS is associated with age and may vary in patients over 50 years old. In many developing countries with an aging population, $\mathrm{BPH}$ associated with LUTS has become a major health issue. To optimize quality of care and control of cost, there is an imperative need to examine the pattern of BPH management. The goal of this study is to capture the Canadian trend in surgical management of $\mathrm{BPH}$ and the use of laser therapy during the last 5 years from 20072008 to 2011-2012.

Methods: We collected the number of transurethral resection of the prostate (TURP) procedures performed in each province in Canada from the Canadian Institute for Health Information (CIHI) reports for the fiscal years (April $1^{\text {st }}$-March 31 ${ }^{\text {st }}$ ) of 2007-2008, 2008-2009, 2009-2010, 2010-2011 and 2011-2012.

Results: Overall, the total number of TURP procedures remained stable from 20294 procedures per year in 2007 to 20629 in 2011. In terms of distribution according to provinces, in 2011, about $40 \%$ of procedures were performed in Ontario, 20\% in BC, 18 in Quebec and $8 \%$ in Alberta. These proportions between provinces have remained similar and stable between 2007 and 2011. In contrast, the number of alternative minimally invasive procedures has slowly grown from 767 interventions in 2007 to 1559 in 2011. Overall, laser procedures represented $7.6 \%$ of the total number of BPH surgeries in Canada in 2011. The contribution of laser therapy to the amount of total $\mathrm{BPH}$ procedures largely varied between provinces.

Conclusions: The use of minimally invasive laser procedure alternatives to TURP is progressively growing. Among the novel laser therapies, HoLEP and GreenLight vaporization are the only procedures that have demonstrated equivalent outcomes compared to TURP in randomized clinical trials. Furthermore, due to shorter hospital stay, these novel laser modalities have the potential to reduce healthcare expenses for the treatment of $\mathrm{BPH}$. We can infer that following the trend observed in the United States, the number of laser therapies for BPH in Canada may increase significantly during the coming years.

\section{Introduction}

Benign prostatic hyperplasia (BPH) is defined pathologically by cellular proliferation of the epithelial and stromal component of the prostate gland. Clinically $\mathrm{BPH}$ is classically associated by the progressive development of lower urinary tract symptoms (LUTS). These symptoms include nocturia, weak urinary stream, hesitancy, incomplete emptying, frequency and urgency. Although other factors have been implicated in the development of LUTS, including dynamic change of the bladder detrusor, the onset of these symptoms is largely attributed to the growing prostate causing bladder outlet obstruction (BOO). ${ }^{1}$ The incidence of bothersome LUTS is associated with age and as measured by the International Prostate Symptom Score (IPSS) may vary from 30 to $40 \%$ in patients over 50 years old. ${ }^{2}$ Thus in many developing countries with an aging population, $\mathrm{BPH}$ associated with LUTS has become a major health issue. It is estimated that by 2018, about 2.578 million patients will be suffering from moderate to severe LUTS that requires treatment. ${ }^{3}$ To optimize quality of care and control of cost, there is an imperative need to examine the pattern of $\mathrm{BPH}$ management.

According to Canadian Urological Association guidelines, patients with mild symptoms should be followed with an approach combining lifestyle modification and watchful waiting. ${ }^{1}$ Medical treatment with adrenergic blockers and 5 alpha-reductase inhibitors (5-ARIs) is considered first-line treatment for men with bothersome LUTS who desire treatment. Alpha-blockers, by relaxing the smooth muscle cells of the prostate and 5-ARIs, by reducing prostate volume, both improve symptoms associated with prostate obstruction. Surgical treatment is indicated when $\mathrm{BPH}$ is associated with urinary retention, renal insufficiency, bladder stone, 
recurrent urinary tract infection or recurrent persistent prostatic bleeding. ${ }^{4}$ The goal of the surgical management of BPH is to reduce the bulk of the prostate to relieve obstruction of the urinary tract.

Today, the most common reason for BPH surgical intervention is LUTS refractory to maximum medical therapy. Transurethral resection of the prostate (TURP) has been the mainstay of surgical therapy for BPH during the last century and remains today the unopposed standard treatment for these patients. ${ }^{4}$ However, during the last decade, a plethora of minimally invasive therapies have been developed in the search for an efficient yet safer alternative to this traditional approach. In particular, minimally invasive laser treatments including transurethral holmium laser enucleation of the prostate (HoLEP) and photoselective vaporization of the prostate (PVP) are currently challenging TURP as the first line surgical treatment of choice. ${ }^{5-8}$

After more than decades of decline in $\mathrm{BPH}$ surgeries largely represented by TURP, an increased rate of BPH surgeries is observed and is largely driven by the novel laser treatments. In fact in the United States, TURPs represent a minority of all $\mathrm{BPH}$ procedures and continues to decline, while GreenLight (AMS, Minnetonka, MN) vaporization of the prostate is the fastest growing modality. ${ }^{9}$

The goal of this study is to capture the Canadian trend in surgical management of $\mathrm{BPH}$ and the use of laser therapy during the last 5 years from 2007-2008 to 2011-2012.

\section{Methods}

The number of TURP procedures performed in each province in Canada was obtained from the Canadian Institute for Health Information $(\mathrm{CIHI})$ reports for the fiscal years (April 1-March 31) of 2007-2008, 2008-2009, 2009-2010, 2010-2011 and 2011-2012. Territories include Northwest Territories, Nunavut and the Yukon. ClHI collects and analyzes information on health and healthcare in Canada and makes it publicly available. Canada's federal, provincial and territorial governments created $\mathrm{CIHI}$ in 1994 as a not-forprofit, independent organization dedicated to forging a common approach to Canadian health information. ${ }^{10}$ The proportion (in percentage) of laser modalities among the total number of transurethral procedures overall, was calculated based on the Canadian Classification of Health Intervention $(\mathrm{CCl})$ code for the procedures. The total count of TURP and laser therapy includes procedures with the appropriate codes (see Appendix for the codes). There were also no distinguishing codes for those men needing TURP retreatment compared to those men undergoing primary TURP surgery. Records where the specified intervention was cancelled, abandoned or performed out-of-hospital were excluded. The counts in the report represent the number of interventions performed and not the number of patients treated. Although
$\mathrm{CIHI}$ is responsible for ensuring specific data collection standards for the Clinical Administrative databases (CAD), the individual Ministries of Health and/or hospitals decide what to collect to comply with the requirements and laws in place in their jurisdiction. The data here contain only acute inpatient and day surgery records submitted to $\mathrm{ClHI}$ by public hospitals within Canada.

\section{Results}

Overall, the total number of TURP procedures remained stable from 20294 procedures in 2007 to 20629 in 2011. After a small decline below 20000 in the 2009-2010 period, the number of procedures increased by $3 \%$ per year between 2009 and 2011-2012 (Fig. 1). In terms of distribution according to provinces, in 2011 , about $40 \%$ of procedures were performed in Ontario, 20\% in BC, 18 in Quebec and $8 \%$ in Alberta. These proportions between provinces have remained similar and stable between 2007 and 2011 (Table 1a).

In contrast, the number of alternative minimally invasive procedures has slowly grown from 767 interventions in 2007 to 1559 in 2011 . This increase corresponds to a $15 \%$ to $25 \%$ growth per year during this period (Fig. 2).

Overall, laser procedures represented $7.6 \%$ of the total number of BPH surgeries in Canada in 2011. The contribution of laser therapy to the amount of total $\mathrm{BPH}$ procedures largely varied between provinces. Laser treatment accounted for up to $20 \%$ in Manitoba, $15 \%$ in New Brunswick and $12.7 \%$ in British Columbia. Meanwhile, in Ontario, Quebec and Alberta, laser technology remained under $10 \%$ and only represented $6 \%$ to $9 \%$ of total $\mathrm{BPH}$ procedures performed in these provinces in 2011 (Table 1b).

\section{Discussion}

$\mathrm{BPH}$ is one of the most common urological disorders and its surgical management has been constantly changing for the last two decades. TURP, as the gold standard, has prevailed for the last century, yet it has been recently challenged by novel minimally invasive procedures, in particular laser procedures.

In Canada, the annual total number of $\mathrm{BPH}$ transurethral procedures has been stable from 2007-2008 to 2011-2012. TURP remains the primary form of surgical therapy for $\mathrm{BPH}$, still representing more $90 \%$ of all procedures in 2011. In contrast, in the United States, TURP represented less than $40 \%$ of the BPH procedures during the same period. ${ }^{6}$

Despite a continuous increase in the usage of laser therapy between 2007 and 2011, the total number of laser therapies in Canada represents only $7.6 \%$ of all BPH transurethral procedures in 2011.

Interestingly, there is wide disparity in the use of laser modalities among provinces. 


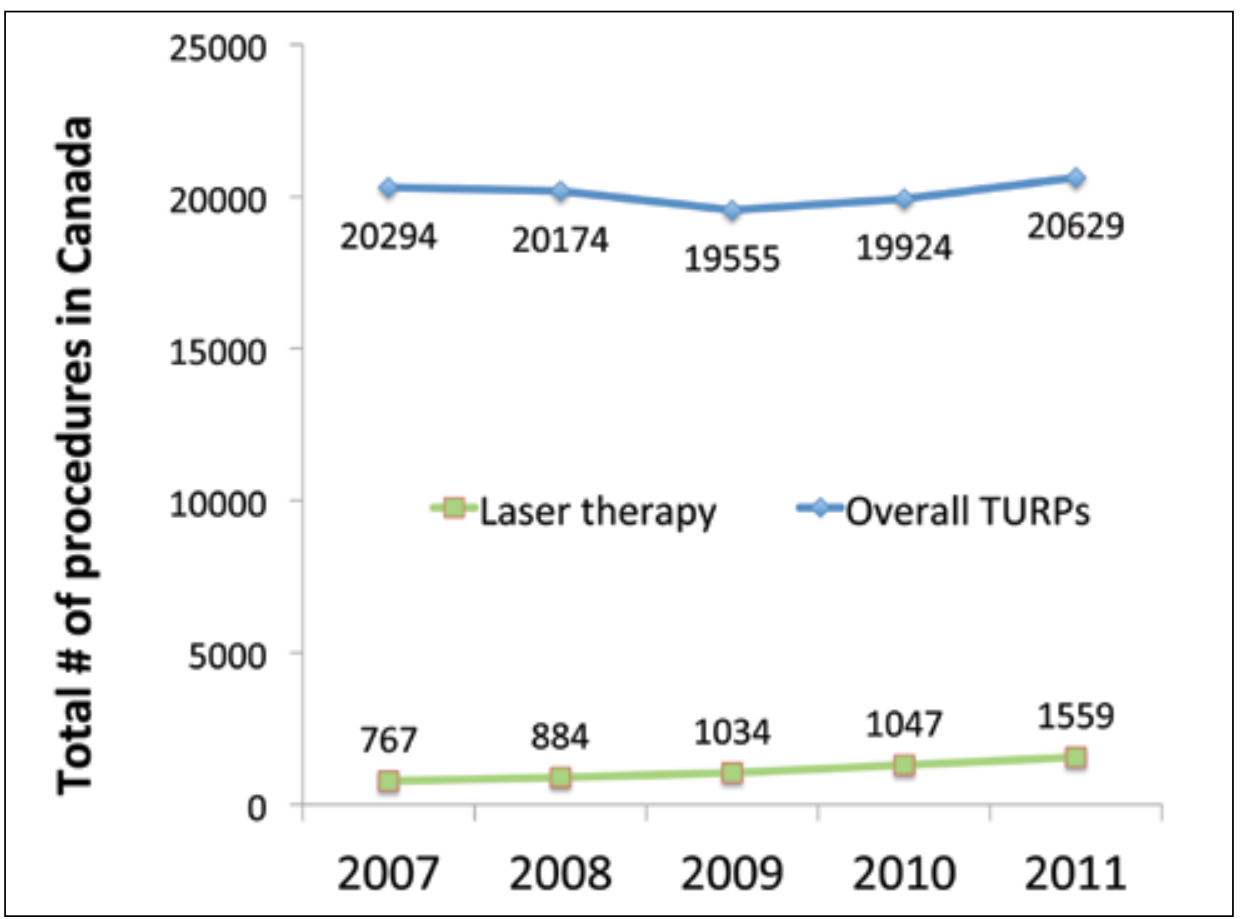

Fig. 1. Total count of transurethral procedures (TURPs) and total number of laser transurethral procedures performed in Canada from 2007-2008 to 2011-2012.

Although not surprising, most of the laser procedures in Canada are performed in Ontario, Quebec and British Columbia (Fig. 2). However in terms of proportion of total $\mathrm{BPH}$ procedures, laser therapy is more prevalent in Manitoba, New Brunswick and British Columbia representing $20 \%, 15$ and $17 \%$ of total BPH procedures, respectively, in 2011. This number suggests an increasing widespread use of laser modalities in these provinces compared to the rest of Canada. This discrepancy between provinces may be explained by a variable availability of technologies possibly due to acquisition costs. Another factor that may contribute to these variations may relate to different reimbursement incentive and insurance coverage (Table 3 ).

\begin{tabular}{|c|c|c|c|c|c|}
\hline Province & 2007 & 2008 & 2009 & 2010 & 2011 \\
\hline $\mathrm{AB}$ & 8.3 & 7.2 & 7.4 & 8.1 & 8.6 \\
\hline$B C$ & 20.4 & 20.3 & 20 & 20.75 & 19.1 \\
\hline MB & 2.5 & 2.4 & 2.1 & 2.73 & 2.5 \\
\hline NB & 3.9 & 4 & 3.3 & 3.1 & 2.9 \\
\hline NL & 3.4 & 1.3 & 1.7 & 1.82 & 2.1 \\
\hline NS & 1.3 & 3.2 & 3.1 & 3.04 & 3 \\
\hline ON & 39.9 & 41.4 & 41.3 & 39.8 & 40.4 \\
\hline PEI & 0.5 & 0.8 & 0.6 & 0.6 & 0.7 \\
\hline OC & 17.3 & 17.5 & 18.8 & 18.45 & 18.4 \\
\hline SK & 2.4 & 1.9 & 1.7 & 1.6 & 2.3 \\
\hline TERR & 0.1 & 0 & 0 & 0.05 & 0 \\
\hline
\end{tabular}

Unfortunately, in this study we were not able to discriminate between laser therapy procedure alternatives to TURPs. The two contemporary and most established laser procedures are holmium enucleation of the prostate (HoLEP) and GreenLight laser vaporization of the prostate (PVP). During the HoLEP, the prostatic adenoma is separated from the capsule in a very similar fashion to open prostatectomy. Ablation of the tissue results from the strong absorption of holmium laser energy $(\mathrm{Ho})$ :YAG lasers $(\lambda=2100 \mathrm{~nm}$ ) by water causing vaporization.

HoLEP is considered an endourological alternative to open prostatectomy. Several randomized trials comparing

\begin{tabular}{|c|c|c|c|c|c|}
\hline Province & 2007 & 2008 & 2009 & 2010 & 2011 \\
\hline$A B$ & 1.9 & 5 & 7.3 & 11.6 & 7.5 \\
\hline $\mathrm{BC}$ & 2.2 & 1.8 & 3.6 & 5.4 & 12.7 \\
\hline $\mathrm{MB}$ & 15.5 & 13 & 17.2 & 16.2 & 20 \\
\hline NB & 1 & 8.6 & 8.7 & 5.9 & 15.6 \\
\hline $\mathrm{NL}$ & 0 & 0 & 0.6 & 0.3 & 0.5 \\
\hline NS & 0 & 0.6 & 0.3 & 1.1 & 0 \\
\hline ON & 4.7 & 5.1 & 5.7 & 6.2 & 8.8 \\
\hline PEI & 0 & 0 & 0 & 0.0 & 0 \\
\hline OC & 4.6 & 3.8 & 4.1 & 6.7 & 6.4 \\
\hline SK & 3.3 & 7 & 12.3 & 3.7 & 3.6 \\
\hline TERR & 0 & 0 & 0 & 0 & 0 \\
\hline
\end{tabular}

Territories (Terr) include Northwest Territories, Nunavut and the Yukon. 


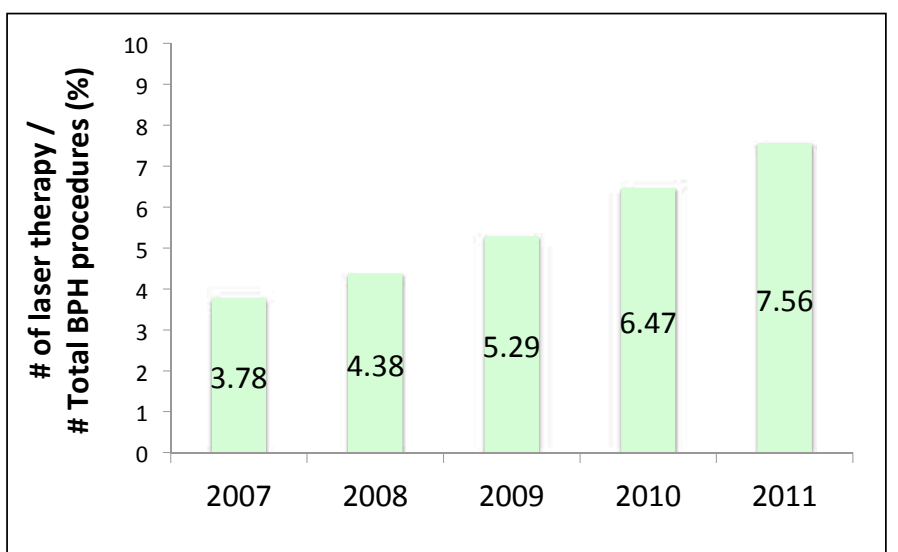

Fig. 2. Number of laser procedures performed in Canada for benign prostatic hyperplasia (BPH).

the two approaches have shown similar outcomes, whereas catheterization time, hospital stay and blood loss were reduced in the HoLEP group. ${ }^{7}$ However, despite excellent long-term durable results independently of prostate size, HoLEP has not gained widespread use among urologists. This limited diffusion is attributed to its technical difficulty and steep learning curve. ${ }^{8}$

GreenLight laser $(\lambda=532 \mathrm{~nm})$ is derived from a Nd:YAG laser that is converted from $1064 \mathrm{~nm}$ to $532 \mathrm{~nm}$ wavelength by the passage through KTP or LBO crystal. The resulting green laser beam is strongly absorbed by oxyhemoglobin. In well-vascularized prostatic tissue, the density of absorbed power is high, raising the tissue temperature above the boiling point causing photoselective vaporization. Vaporization of the superficial tissue, with a minimal rim of coagulation, allows the creation of a TUR-like cavity. Several advantages, such as reduced bleeding complications and shorter hospital stay, have been clearly demonstrated for GreenLight PVP. In contrast to HoLEP, Greenlight PVP has gained wide acceptance and diffusion worldwide despite the paucity of evidence supporting its use as first-line treatment. In the United States, laser vaporization of the prostate continues to rise and is the fastest growing modality accounting for $30 \%$ of all BPH procedures in 2008. The relatively short learning curve combined with the better perioperative profile may provide a simple explanation to this change in surgi-

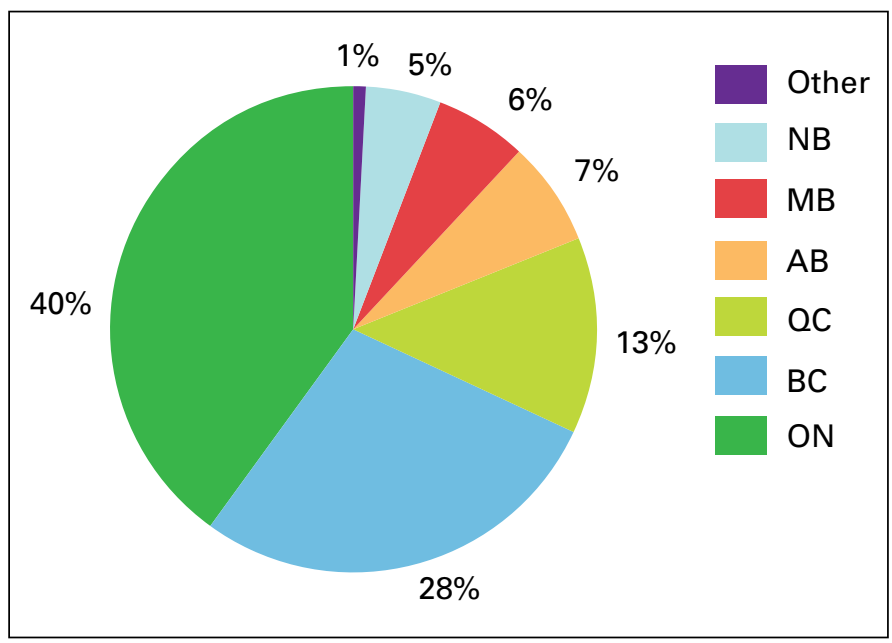

Fig. 3. Laser procedure distribution according to province as a percentage of total laser procedures, 2011-2012 (other includes SK, NS, PEI and Territories).

cal trend..$^{-2,6}$ Nevertheless several questions remain with GreenLight vaporization, such as long-term durability of outcomes and higher retreatment rate in patients with larger prostates. ${ }^{9}$ Although these issues may be addressed by the latest version XPS-180W GreenLight system developed with an increased power providing an increased energy capacity delivery and more efficient tissue removal, this remains to be demonstrated in long-term trials. ${ }^{11-13}$

In Canada's publicly funded healthcare system, cost is an important factor to consider when adopting a novel treatment approach. Interestingly, several studies have shown that laser therapy, such as HoLEP and GreenLight PVP, have significant cost advantage compared to TURP mainly due to shorter hospitalization stay and less morbidity. ${ }^{14,15}$

Since the introduction of medical therapy, the incidence of acute urinary retention and $\mathrm{BPH}$ surgeries has decreased. ${ }^{16}$ However, patients who finally require BPH surgery are inevitably older, have larger prostate, have worse health conditions and therefore are at higher risk of surgical complications. ${ }^{17}$ As a corollary, older patients are at higher risk to be on anticoagulant therapy, which makes them less than ideal candidates for traditional approaches, such as TURP or open prostatectomy. With regards to intra-operative safety, GreenLight laser vaporization has been demonstrated supe-

\begin{tabular}{|c|c|c|c|c|c|c|c|c|c|c|}
\hline 2010 & $A B$ & BC & MB & NB & NL & NS & ON & PEI & OC & SK \\
\hline \multicolumn{11}{|l|}{ TURP } \\
\hline $\begin{array}{l}\text { Code } \\
\text { Fee (CAN\$) }\end{array}$ & $\begin{array}{l}72.1 \mathrm{~A} \\
488.5\end{array}$ & $\begin{array}{l}8311 \\
465.2\end{array}$ & $\begin{array}{l}4321 \\
512.7\end{array}$ & $\begin{array}{c}1394 \\
394\end{array}$ & $\begin{array}{r}97640 \\
514.6\end{array}$ & $\begin{array}{c}72.1 \mathrm{~B} \\
540\end{array}$ & $\begin{array}{c}S 655 \\
450\end{array}$ & $\begin{array}{l}8584 \\
514.6\end{array}$ & $\begin{array}{c}6247 \\
394\end{array}$ & $\begin{array}{c}123 R \\
586\end{array}$ \\
\hline \multicolumn{11}{|l|}{ Laser } \\
\hline $\begin{array}{l}\text { Exception } \\
\text { Code Fee (CAN\$) }\end{array}$ & $\begin{array}{c}\text { PVP } \\
72.1 \mathrm{C} \\
659.48\end{array}$ & $\begin{array}{c}\text { HoLEP }>60 \mathrm{~g} \\
\text { PS81311 } \\
930.4\end{array}$ & Idem & Idem & Idem & Idem & Idem & Idem & $\begin{array}{c}\text { All laser } \\
6239 \\
363\end{array}$ & Idem \\
\hline
\end{tabular}

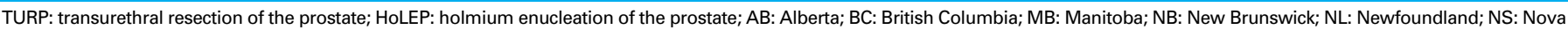
Scotia; ON: Ontario; PEI: Prince Edward Island; QC: Quebec; SK: Saskatchewan. 
rior to TURP and therefore should be considered in these higher risk patients receiving anticoagulant medication or with a high cardiovascular risk.

\section{Strength and limitations}

To the best of our knowledge, this is the first study reporting on the surgical distribution of BPH procedures in Canada. $\mathrm{CIHI}$ data should include all acute inpatient and day surgery patients performed in public hospitals within Canada. Nevertheless, it is possible that some data from urological practices in Canada were not submitted to $\mathrm{CIHI}$. A limitation of this study is that Canadian Classification of Health Intervention $(\mathrm{CCl})$ codes do not distinguish among procedures other than TURP and laser. The numbers presented here represent the count of interventions performed and not the count of patients. Therefore, during the fiscal years of interest, it is possible that a patient underwent multiple procedures. Nevertheless, we can accept that these numbers remain an estimation of the number of patients treated (as the 1 - to 5 -year retreatment rate is likely to be under $5 \%$ ). Thus, the counts represent the number of occurrences and not the number of patients who have had TURP. Furthermore, the counts did not include records where the specified intervention was cancelled, abandoned or performed out-of-hospital.

\section{Conclusion}

In Canada, while TURP still represents more than $90 \%$ of the $\mathrm{BPH}$ procedures, the use of minimally invasive laser procedure alternatives is progressively growing. Among the novel laser therapies, HoLEP and GreenLight vaporization are the only procedures that have demonstrated equivalent outcomes compared to TURP in randomized clinical trials. Furthermore, due to shorter hospital stay, these novel laser modalities have the potential to reduce healthcare expenses for the treatment of $\mathrm{BPH}$.

We can infer that following the American trend, the number of laser therapies, particularly GreenLight vaporization, for $\mathrm{BPH}$ in Canada may increase significantly during the coming years.

Competing interests: Dr. Zorn is a consultant for American Medical Systems.

This paper has been peer-reviewed.

\section{References}

1. Nickel JC, Mendez-Probst CE, Whelan TF, et al. 2010 Update: Guidelines for the management of benign prostatic hyperplasia. Can Urol Assoc J 2010;4:310-6. http://dx.doi.org/10.5489/cuaj.10124
2. Al-Ansari A, Younes N, Sampige VP, et al. Greenlight HPS 120-W laser vaporization versus transurethral resection of the prostate for treatment of benign prostatic hyperplasia: a randomized clinical trial with midterm follow-up. Eur Urol 2010;58:349-55. http://dx.doi.org/10.1016/i.eururo.2010.05.026

3. Capitan C, Blazquez C, Martin MD, et al. GreenLight HPS 120-W laser vaporization versus transurethral resection of the prostate for the treatment of lower urinary tract symptoms due to benign prostatic hyperplasia: a randomized clinical trial with 2-year follow-up. Eur Urol 2011;60:734-9. http://dx.doi. org/10.1016/i.eururo.2011.05.043

4. Lukacs B, Loeffler J, Bruyere F, et al. Photoselective vaporization of the prostate with Greenlight 120-W laser compared with monopolar transurethral resection of the prostate: a multicenter randomized controlled trial. Eur Urol 2012;61:1165-73. http://dx.doi.org/10.1016/i.eururo.2012.01.052

5. van Rii S, Gilling PJ. In 2013, Holmium Laser Enucleation of the Prostate (HoLEP) May Be the New Gold Standard. Curr Urol Rep 2012;13:427-32.

6. Malaeb BS, Yu X, McBean AM, et al. National trends in surgical therapy for benign prostatic hyperplasia in the United States (2000-2008). Urology 2012;79:1111-7. http://dx.doi.org/10.1016/j. urology.2011.11.084

7. Elzayat EA, Elhilali MM. Holmium laser enucleation of the prostate (HoLEP): the endourologic alternative to open prostatectomy. Eur Urol 2006;49:87-91. http://dx.doi.org/10.1016/i.eururo.2005.08.015

8. Gilling PJ, Wilson LC, King CJ, et al. Long-term results of a randomized trial comparing holmium laser enucleation of the prostate and transurethral resection of the prostate: results at 7 years. BJU Int 2012;109:408-11. Epub 2011 Aug 23.

9. Hueber PA, Ben-Zvi T, Liberman D, et al. Mid term outcomes of initial 250 case experience with GreenLight 120W-HPS photoselective vaporization prostatectomy for benign prostatic hyperplasia: comparison of prostate volumes $<60 \mathrm{cc}, 60 \mathrm{cc}-100 \mathrm{cc}$ and $>100 \mathrm{cc}$. Can J Urol 2012;19:6450-8.

10. Canadian Institute for Health Information. http://www.cihi.ca. Accessed September 4, 2013.

11. Ben-Zvi T, Hueber PA, Liberman D, et al. GreenLight XPS 180W vs HPS 120W Laser Therapy for Benign Prostate Hyperplasia: A Prospective Comparative Analysis After 200 Cases in a Single-center Study. Urology 2013;81:853-8. Epub 2013 Feb 13. htrp://dx.doi.org/10.1016/j.urology.2012.12.031

12. Zorn KC, Liberman D. GreenLight 180W XPS photovaporization of the prostate: how I do it. Can J Urol 2011;18:5918-26.

13. Bachmann A, Muir GH, Collins EJ, et al. 180-W XPS Greenlight laser therapy for benign prostate hyperplasia: early safety, efficacy, and perioperative outcome after 201 procedures. Eur Urol 2012;61:600-7. http://dx.doi.org/10.1016/i.eururo.2011.11.041

14. Fraundorfer MR, Gilling PJ, Kennett KM, et al. Holmium laser resection of the prostate is more cost effective than transurethral resection of the prostate: results of a randomized prospective study. Urology 2001;57:454-8. http://dx.doi.org/10.1016/S0090-4295(00)00987-0

15. Liatsikos E, Kyriazis I, Kallidonis $\mathrm{P}$, et al. Photoselective Greenlight laser vaporization versus transurethral resection of the prostate in Greece: a comparative cost analysis. J Endourol 2012;26:168-73. http:// dx.doi.org/10.1089/end.2011.0089

16. McConnell JD, Roehrborn CG, Bautista OM, et al. The long-term effect of doxazosin, finasteride, and combination therapy on the clinical progression of benign prostatic hyperplasia. N Engl J Med 2003;349:238798. http://dx.doi.org/10.1056/NEJMoa030656

17. Choi SY, Kim TH, Myung SC, et al. Impact of changing trends in medical therapy on surgery for benign prostatic hyperplasia over two decades. Korean J Urol 2012;53:23-8. http://dx.doi.org/10.4111/ kju.2012.53.1.23

Correspondence: Dr. Kevin Zorn, University of Montréal Hospital Centre, 235 Boul. Rene Levesque East, Suite 301, Montréal, QC H2X 1N8; kevin.zorn@gmail.com

\section{Appendix. CIHI Codes}

1.QT.87.BA

1.QT.87.BA-AG

1.QT.87.BA-AK
- Refers to excision partial, prostate using device NEC endoscopic transurethral approach

- Refers to excision partial, prostate using laser endoscopic transurethral approach

- Laser Therapy count included coded 1.QT.87.BA-AG with no distinction between laser technologies or techniques.

- Refers to excision partial, prostate using loop electrode endoscopic transurethral approach
CIHI: Canadian Institute for Health Information. 